\title{
SEQUENTIAL ANAEROBIC-AEROBIC DEGRADATION OF INDIGENOUS PCBS IN A CONTAMINATED SOIL MATRIX
}

K. T. Klasson, M. E. Reeves, B. S. Evans, and C. A. Dudley

Chemical Technology Division

Oak Ridge National Laboratory ${ }^{1}$

Oak Ridge, Tennessee 37831-6044

PRESENTATION/PUBLICATION

For presentation at

IGT's Seventh International Symposium on Gas, Oil, and Environmental Biotechnology

December 12-14, 1994

Colorado Springs, Colorado
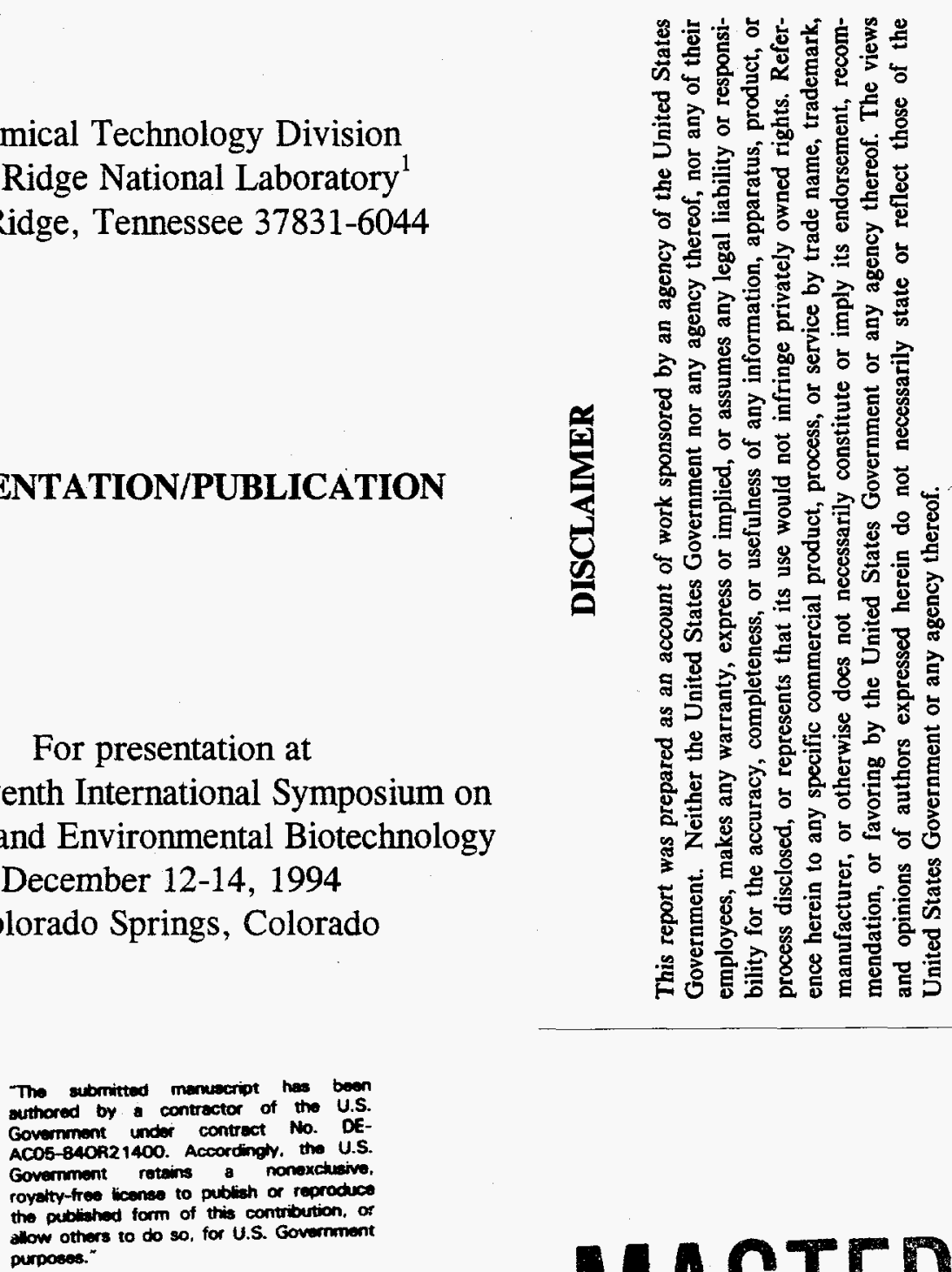

MASTER

${ }^{1}$ Managed by Martin Marietta Energy Systems, Inc., for the US Department of Energy under contract DE-AC05-84OR21400 


\section{DISCLAIMER}

Portions of this document may be illegible in electronic image products. Images are produced from the best available original document. 


\title{
SEQUENTIAL ANAEROBIC-AEROBIC DEGRADATION OF INDIGENOUS PCBS IN A CONTAMINATED SOIL MATRIX
}

\author{
K. Thomas Klasson, Ph.D. \\ Mark E. Reeves, Ph.D. \\ Betty S. Evans, A.E. \\ Connie A. Dudley \\ Chemical Technology Division \\ Oak Ridge National Laboratory \\ Oak Ridge, Tennessee 37831-6044, USA
}

\begin{abstract}
Many industrial locations, including the US Department of Energy's, have identified needs for treatment of polychlorinated biphenyl (PCB) wastes and remediation of PCB-contaminated sites. Biodegradation of PCBs is a potentially effective technology for the treatment of PCB-contaminated soils and sludges; however, a practicable remediation technology has not yet been demonstrated. A biological treatment technology is likely to consist of an anaerobic fermentation step in which PCB dechlorination takes place producing PCBs with fewer chlorines. These products are then more susceptible to aerobic mineralization.

In laboratory experiments, soil slurry bioreactors inoculated with microorganisms extracted from PCB-contaminated sediments from the Hudson River and Woods Pond have been used to obtain anaerobic dechlorination of PCBs in soil slurry reactors. The anaerobic dechlorination was followed by qualitative estimation of the effect of aerobic fermentation of the dechlorination products based on literature data. The sequential anaerobic-(simulated) aerobic treatment constituted an improvement compared anaerobic treatment alone.
\end{abstract}




\section{SEQUENTIAL ANAEROBIC-AEROBIC DEGRADATION OF INDIGENOUS PCBS IN A CONTAMINATED SOIL MATRIX}

\section{INTRODUCTION}

Polychlorinated biphenyls (PCBs) are a family of compounds that were used extensively in many industrial applications until the mid -1970 s. They were produced as complex mixtures by direct chlorination of biphenyl and were marketed for use in transformers, capacitors, printing ink, paints, antidusting agents, pesticides, etc. The mixtures were marketed under various trade names (Aroclor, Clophen, Kanechlor, Phenoclor, and Pyralene) with associated numbers denoting the average chlorine content [e.g., Aroclor 1242, manufactured by Monsanto, contains $42 \%$ (by weight) chlorine].

The discovery of widespread environmental occurrence of these very stable compounds and the suspected carcinogenic effect in humans led to the regulation of PCBs through the Toxic Substances Control Act (TSCA) in 1976. Although not in production, PCBs have persisted in the environment and it is estimated that several million pounds were released into the environment prior to the ban [1].

Although PCBs may seem to be inert, the aerobic microbial degradation of lower chlorinated PCBs is well known and has been studied extensively. Recently, the anaerobic reductive dechlorination of PCBs by microorganisms in river sediments has also been studied. A review by Abramowicz [2] summarizes research results on both the aerobic and anaerobic bioprocesses. The complete biodegradation of PCBs to form nonhazardous end products is complex and consists of three stages: (1) partial dechlorination to 3 to 4 chlorines per biphenyl under anaerobic conditions; (2) aerobic attack on the biphenyl rings to cause ring cleavage; and (3) mineralization of the chlorinated benzoic acids to form $\mathrm{H}_{2} \mathrm{O}, \mathrm{CO}_{2}, \mathrm{Cl}^{-}$, and cell mass. Most of the current research is directed toward the first stage, because it is believed that this stage is the rate limiting.

The anaerobic dechlorination has been observed in river and pond sediments and has been proven and repeated in laboratory settings. Isolation of dechlorinating organisms is difficult, and mixed cultures capable of PCB dechlorination found at a specific site tend to lose their activities when transferred to another matrix void of humic acids [3]. The treatment period (or incubation period) is on the order of several months, but methods have been developed to enhance or induce dechlorination of halogenated aromatics and thus shorten the incubation period. The most commonly used methods involve nutrient amendments $[4,5,6,7]$ and the addition of specific polyhalogenated biphenyls $[8,9]$. Results of the sequential anaerobic-aerobic treatment of PCB-contaminated soils have been published by Shannon, et al. [10], but few details about the procedure were presented.

This work presents the results of anaerobic dechlorination studies performed with historically PCB-contaminated soil and the anticipated effect of aerobic treatment subsequent to the anaerobic phase. The studies were performed in (river) sediment-free 
soil slurry reactors and represent the rare case in which the anaerobic consortia have been successfully transferred from native river sediments to soil with a very low organic content. Anaerobic studies with PCB-contaminated soils were performed by Tiedje, et al. by combining non-contaminated sediments (as a source of bacteria and humic acids) and contaminated soil to form sediment/soil slurries [11]. The effect of carbon source and single congener additions on dechlorination in (river) sediment-free slurry reactors have been published previously by us [12].

\section{EXPERIMENTAL SECTION}

\section{Soil Collection}

PCB-contaminated soil was collected from a capacitor bank at a power substation located in Chattanooga, Tennessee. Over time, PCBs have been released through spills in and around the capacitors. The soil had the following characteristics:

$26.1 \%$ clay, $24.7 \%$ sand, $49.2 \%$ silt, $0.86 \%$ organic matter, and $0.08 \%$ total nitrogen; $\mathrm{pH}$ of 8.1. The soil was combined with sterile water (equal volumes), and the slurry was ball milled antiseptically and anaerobically for $4 \mathrm{~h}$ to ensure homogeneity. The PCB concentration was $\sim 40 \mathrm{ppm}$ in the dry soil, and the congener pattern resembled Aroclor 1248 or Aroclor 1254.

\section{Anaerobic Slurry Reactor Study}

Batch incubations were prepared under an anaerobic (nitrogen) environment in 150-mL nominal-volume serum bottles (Wheaton Scientific, Millville, NJ), and the bottles were capped with Teflon-lined caps (The West Co., Phoenixville, PA) and aluminum crimp-seals (Wheaton).

The final concentrations of nutrients in the bioreactors were (per liter): $200 \mathrm{~g}$ soil, $1 \mathrm{~g}$ yeast extract/nutrient broth, $2.3 \mathrm{~g}$ acetone, $1.2 \mathrm{~g} \mathrm{NaHCO}_{3}, 525 \mathrm{mg} \mathrm{NH}_{4} \mathrm{Cl}$, $100 \mathrm{mg} \mathrm{MgCl} \cdot 6 \mathrm{H}_{2} \mathrm{O}, 75 \mathrm{mg} \mathrm{CaCl}, 35 \mathrm{mg} \mathrm{K} \mathrm{HPO}_{4}, 27 \mathrm{mg} \mathrm{KH}_{2} \mathrm{PO}_{4}, 21.5 \mathrm{mg}$ $\mathrm{FeCl}_{2} \cdot 4 \mathrm{H}_{2} \mathrm{O}, 300 \mu \mathrm{g} \mathrm{H}_{3} \mathrm{BO}_{3}, 200 \mu \mathrm{g} \mathrm{CoCl} \cdot 6 \mathrm{H}_{2} \mathrm{O}, 100 \mu \mathrm{g} \mathrm{ZnSO}_{4} \cdot 7 \mathrm{H}_{2} \mathrm{O}, 30 \mu \mathrm{g}$ $\mathrm{MnCl}_{2} \cdot 4 \mathrm{H}_{2} \mathrm{O}, 30 \mu \mathrm{g} \mathrm{Na} \mathrm{MoO}_{4} \cdot 2 \mathrm{H}_{2} \mathrm{O}, 20 \mu \mathrm{g} \mathrm{NiCl} \cdot 6 \mathrm{H}_{2} \mathrm{O}, 10 \mu \mathrm{g} \mathrm{CuCl} \cdot \mathrm{H}_{2} \mathrm{O}, 10 \mu \mathrm{g}$ $\mathrm{Na}_{2} \mathrm{SeO}_{3}$, and $1 \mathrm{mg}$ resazurin. The final $\mathrm{pH}$ of the slurry was 7 to 7.5 , and the total slurry volume in each reactor was $35.1 \mathrm{~mL}$. The reactors were incubated stationary in the dark at room temperature. Abiotic controls were incubated and sampled with no measurable dechlorination.

\section{Inoculum}

Naturally occurring organisms present in the Hudson River and Woods Pond sediments have been shown to be responsible for extensive dechlorination of PCBs in that environment [13]. The inoculum was prepared from equal volumes of dewatered sediments and mineral medium. The slurry was mixed for $1 \mathrm{~h}$ followed by a 15 -min settling time. The supernatant was removed and filtered through a cotton filter before use. One reactor was inoculated with a medium containing organisms present in Hudson River (NY) sediments and the other reactor was inoculated with a medium 
containing organisms present in Woods Pond (MA) sediments. Each inoculum was added to steam-sterilized medium. Abiotic controls were not inoculated but otherwise identical.

\section{Sampling and PCB Analysis}

One milliliter of slurry was removed at each sampling time and was combined with $1 \mathrm{~mL}$ of acetone and $4 \mathrm{~mL}$ of hexane, shaken for $4 \mathrm{~h}$, and centrifuged at $1000 \mathrm{rpm}$ for $5 \mathrm{~min}$. One milliliter of the organic phase was combined with $0.1 \mathrm{~mL}$ internal standard (octachloronaphtalene in hexane), and $2 \mu \mathrm{L}$ of the mixture was injected into a gas chromatograph (GC) (Hewlett-Packard, Avondale, PA) equipped with an electron capture detector and a 30-m $\times 0.247-\mathrm{mm}$ DB-1 $(0.25 \mu \mathrm{m}$ film thickness) capillary column (J\&W Scientific, Folsom, CA). The splitless/split injector temperature was $270^{\circ} \mathrm{C}$, and the detector temperature was $300^{\circ} \mathrm{C}$. The initial oven temperature was kept at $40^{\circ} \mathrm{C}$ for 2 min, after which two temperature ramps $\left(20^{\circ} \mathrm{C} / \mathrm{min}\right.$ to $160^{\circ} \mathrm{C}$ and $5^{\circ} \mathrm{C} / \mathrm{min}$ thereafter) were used to increase the oven temperature to $270^{\circ} \mathrm{C}$. Calibration was performed using an Aroclor (Ultra Scientific, North Kingstown, RI) mixture of 70\% (by weight) Aroclor $1242,20 \%$ Aroclor 1254 , and $10 \%$ Aroclor 1260 in hexane. The PCB congener composition of the Aroclors needed for calibration was supplied by Dr. Abramowicz (General Electric, Schenectady, NY), and similar data have been published elsewhere [14]. Data analysis using HP Chemstation software (Hewlett-Packard) was conducted on 68 congener-containing peaks. The peak identification has previously been published by Brown et al. [13]. The extracted soil was dried at $80^{\circ} \mathrm{C}$ for $20 \mathrm{~h}$ to determine the dry soil weight of each sample.

\section{PCB Chlorine Content}

The number of mono-, di-, tri-, etc., chlorinated biphenyls were calculated based on the known PCB congener composition in the standards and peak identification mentioned above. The average initial chlorine content was 4.35 chlorines per biphenyl. A decrease in this number indicates a general dechlorination. In addition to the homolog calculations, the mole percentage of congeners in GC peaks was also calculated for the simulation (see next section). This method is not exact since complete congener separation was impossible in the analysis; however, the method is useful to show general trends and allow for comparisons between experiments.

\section{Simulation of Aerobic PCB Degradation}

The possible extent of aerobic degradation was estimated based on published degradation of PCB congeners present in Aroclors 1242, 1248, and 1254 by the commercially available Alcaligenes eutrophus H850 (NRRL 15940) [15]. Each of the products from the anaerobic dechlorination was evaluated for aerobic degradation susceptibility. This allowed for an estimation of the number of mono-, di-, tri-, etc., chlorinated biphenyls present after the simulated aerobic fermentation. Current experiments are verifying the simulated data with actual experimental data. 


\section{DISCUSSION}

Sampling was done at start-up and then every 4 weeks. Typical PCB GC peak profiles for selected reactors at start-up are shown in Figure 1. Evidence of dechlorination was first noted after 20 weeks; dechlorination then steadily progressed for another 20 weeks. The PCB GC peak profiles after 40 weeks of incubation with either organisms from Hudson River or Woods Pond may be seen in Figures 2 and 3. It is clear from inspecting the chromatograms in Figures 1,2 and 3 that there is an increase in peak sizes around 16 to $20 \mathrm{~min} \mathrm{GC}$ retention time and a decrease in sizes for peaks occurring after $20 \mathrm{~min}$. Since in general PCB congeners with fewer chlorines have shorter GC retention times, this shift in peaks is proof of dechlorination. PCB peak profiles from samples taken from the abiotic controls did not change over the 40 week study (data not shown). The PCB GC peak profiles of the anaerobic dechlorination in the soil is very similar to that presented by Shannon et al. [10] indicating similar microbial activation.

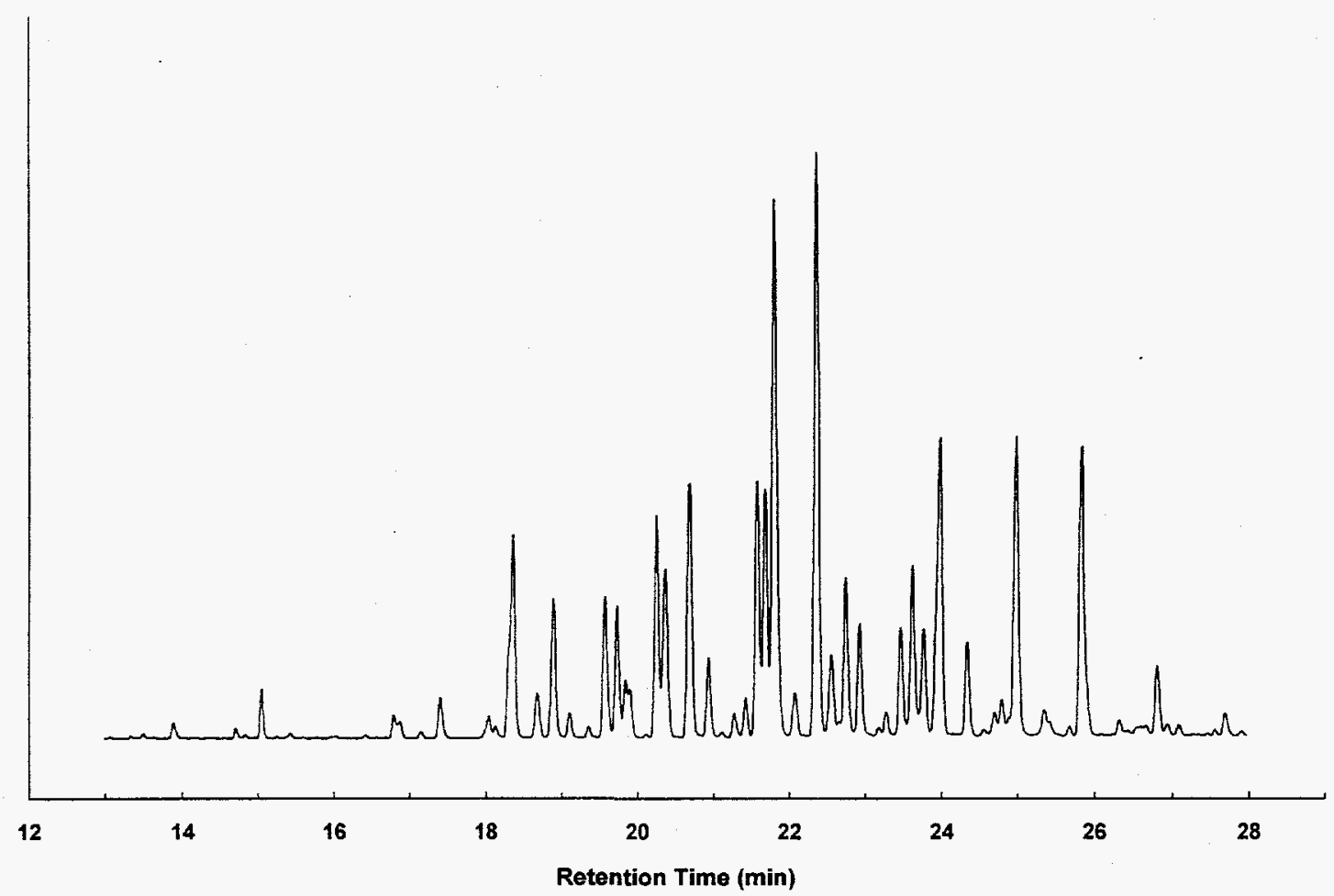

Figure 1. PCB GC peak profile of sample taken from contaminated soil (40 ppm PCB) 


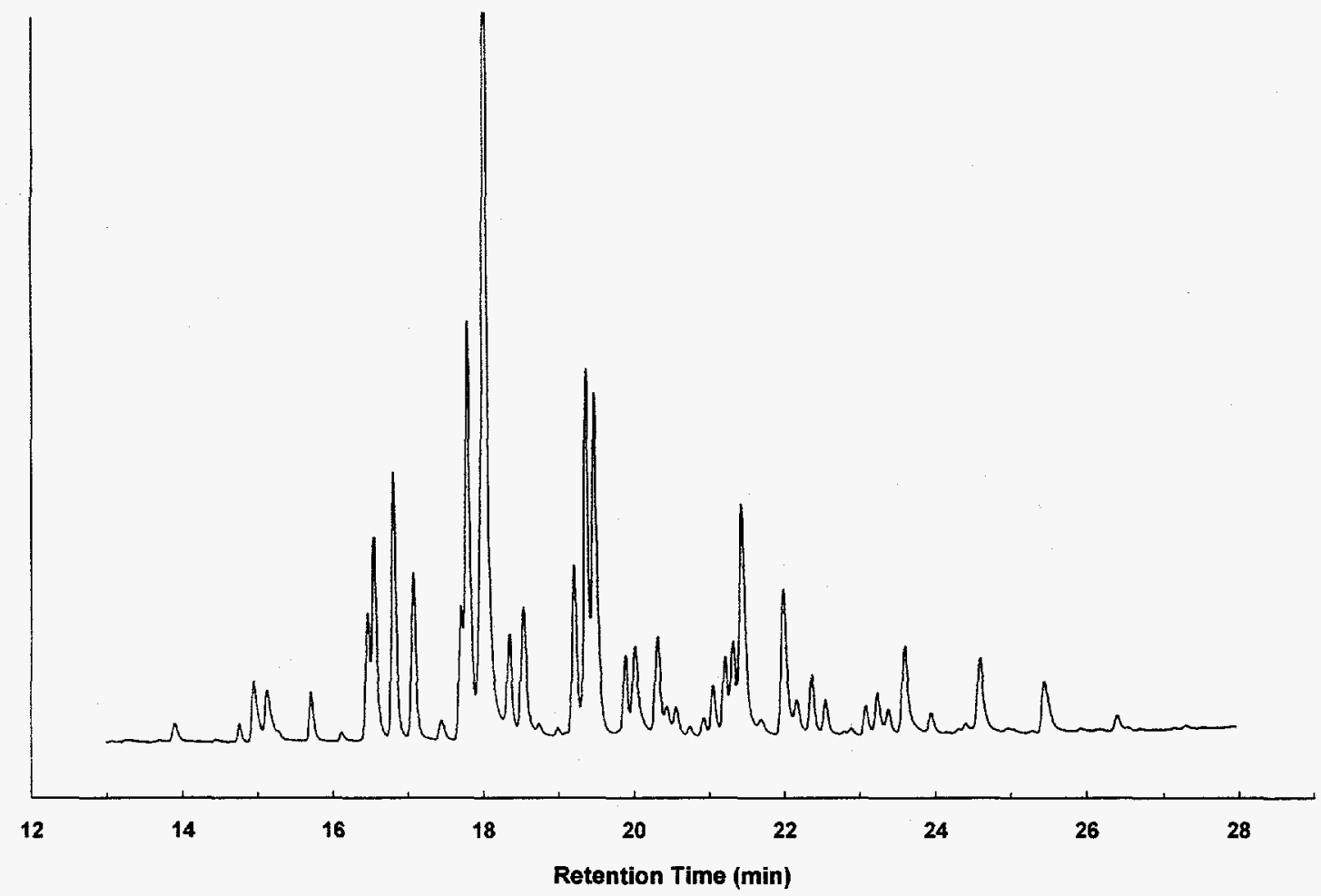

Figure 2. PCB GC profile of sample taken after 40 weeks of incubation with organisms eluted from Hudson River sediments

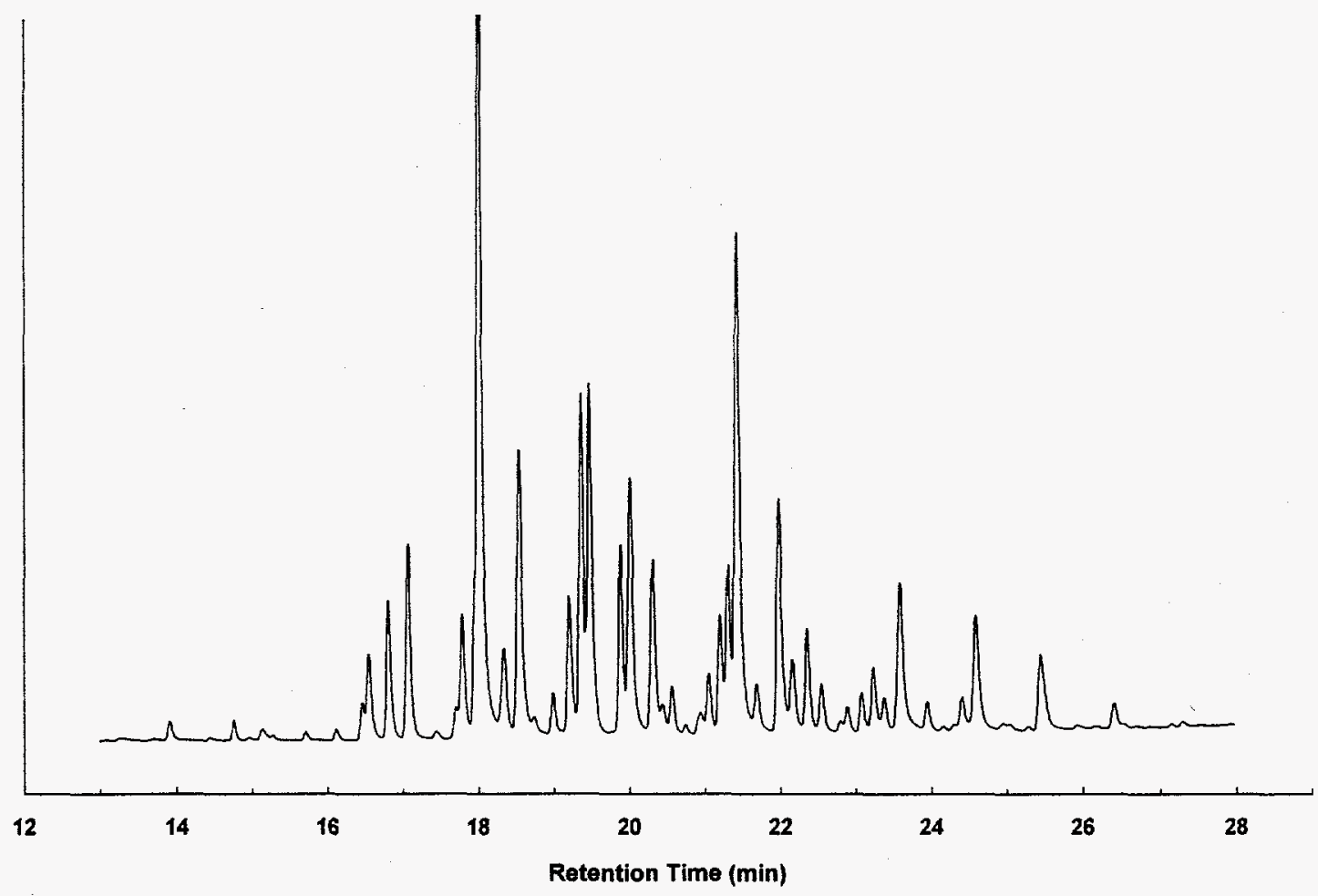

Figure 3. PCB GC profile of sample taken after 40 weeks of incubation with organisms eluted from Woods Pond sediments 
The change in homolog profile during the dechlorination may be noted in Table 1 . A decrease in tetra-, penta, and hexachlorobiphenyl was accompanied by an increase in the di- and trichlorobiphenyls. As is noted in Table 1, the organisms present in Hudson River sediments appears to be slightly more efficient in their dechlorination. The average PCB chlorine content of the dechlorination products in the reactor inoculated with Hudson River organisms was 3.45 after 40 weeks of incubation. Similarly, the average PCB chlorine content was 3.76 in the reactor inoculated for 40 weeks with organisms from Woods Pond.

Table 1. Mole percent of PCB homologs in samples taken at start-up, after 24 weeks, and after 40 weeks on incubation

\begin{tabular}{|lrrrrrrrr||}
\hline & \multicolumn{3}{c}{ Hudson River Organisms } & & \multicolumn{3}{c|}{ Woods Pond Organisms } \\
\cline { 2 - 4 } \cline { 6 - 8 } Homolog & Start-Up & 24 Weeks & 40 Weeks & & Start-Up & 24 Weeks & 40 Weeks \\
\hline \hline Mono & 0 & 0 & 0 & & 0 & 0 & 0 \\
Di & 4.23 & 6.42 & 7.67 & & 2.37 & 1.36 & 2.63 \\
Tri & 13.24 & 44.28 & 53.11 & & 12.76 & 27.61 & 41.67 \\
Tetra & 38.55 & 30.14 & 27.35 & & 39.99 & 41.42 & 35.61 \\
Penta & 36.12 & 15.85 & 10.6 & & 36.49 & 24.61 & 17.88 \\
Hexa & 6.71 & 2.63 & 1.28 & & 7.1 & 4.01 & 2.15 \\
Hepta & 0.92 & 0.53 & 0 & & 1.03 & 0.82 & 0.07 \\
Octa & 0.24 & 0.15 & 0 & & 0.26 & 0.17 & 0 \\
\hline
\end{tabular}

Based on the results of the anaerobic dechlorination and literature data for the aerobic degradation, each of the products from the anaerobic dechlorination was evaluated for aerobic degradation susceptibility. This allowed for an estimation of the number of mono-, di-, tri-, etc., chlorinated biphenyls present after an aerobic fermentation. The result of the calculation may be seen in Table 2. The initial PCB concentration was reduced from $49.6 \mathrm{ppm}$ to $8.3 \mathrm{ppm}$ with some recalcitrant tri-, tetra-, and pentachlorobiphenyls remaining.

Table 2. Homolog concentration (ppm) in soil during the anaerobic incubation of PCBcontaminated soil with Hudson River organisms and the subsequent simulated aerobic phase

\begin{tabular}{|c|c|c|c|c|}
\hline \multirow[b]{2}{*}{ Homolog } & \multicolumn{3}{|c|}{ Anaerobic Incubation } & \multirow{2}{*}{$\begin{array}{l}\text { Aerobic Incubation } \\
\text { Simulation }\end{array}$} \\
\hline & Start-Up & 24 Weeks & 40 Weeks & \\
\hline Mono & $\overline{0.0}$ & $\overline{0.0}$ & 0.0 & 0.0 \\
\hline $\mathrm{Di}$ & 1.2 & 1.9 & 2.2 & 0.1 \\
\hline Tri & 4.5 & 14.9 & 17.9 & 1.8 \\
\hline Tetra & 14.7 & 11.5 & 10.5 & 2.9 \\
\hline Penta & 15.4 & 6.8 & 4.5 & 2.9 \\
\hline Hexa & 3.2 & 1.2 & 0.6 & 0.6 \\
\hline Hepta & 0.5 & 0.3 & 0.0 & 0.0 \\
\hline Octa & 0.1 & 0.1 & 0.0 & 0.0 \\
\hline TOTAL & 39.6 & 36.7 & 35.7 & $\overline{\overline{8.3}}$ \\
\hline
\end{tabular}




\section{CONCLUSIONS}

PCB-dechlorinating microorganisms were successfully transferred from Hudson River and Woods Pond sediments to a sandy soil contaminated with PCBs. Both microbial consortia expressed similar dechlorination activities, the Hudson River organisms slightly better. Higher chlorinated biphenyls were dechlorinated to less chlorinated product that are susceptible to aerobic degradation. A simulated aerobic incubation of the dechlorination products resulted in a decrease of the PCB concentration from $36 \mathrm{ppm}$ to $8 \mathrm{ppm}$. This result clearly show the potential for sequential anaerobicaerobic incubation as a treatment method for PCB-contaminated soils. Current experiments will verify the simulated aerobic incubation results.

\section{ACKNOWLEDGMENTS}

This work was supported by the US Department of Energy's Office of Technology Development. The project is part of a Cooperative Research and Development Agreement between the Oak Ridge National Laboratory and the General Electric Company for collaborative development of bioremediation technologies for PCBs. Oak Ridge National Laboratory is managed by Martin Marietta Energy Systems, Inc., for the US Department of Energy under contract DE-AC05-84OR21400. We thank M. JimBeck of the Tennessee Valley Authority and D. Abramowicz of General Electric Company Corporate R\&D Center for their interactions with us.

\section{REFERENCES CITED}

1. Erickson, M. D., Analytical Chemistry of PCBs, 34. Stoneham, MA: Butterworth Publishers, 1986.

2. Abramowicz, D. A., "Aerobic and Anaerobic Biodegradation of PCBs: A Review," Crit. Rev. Biotechnol. 3, 241-251 (1990).

3. Boyle, A. W., White, N., and May, H. D., "Anaerobic Dechlorination of 2,3,6-Trichlorobiphenyl: An Analysis of the Requirement for Humic Acids and a Determination of Suitable Sources of Carbon and Energy," paper presented at the ASM Conference on Anaerobic Dehalogenation and Its Environmental Implications, Athens, Georgia, August 30-September 4, 1992.

4. Niels, L. and Vogel, T. M., "Effects of Organic Substrates on Dechlorination of Aroclor 1242 in Anaerobic Sediments," Appl. Environ. Microbiol. 56, 26122617 (1990).

5. Linkfield, T. G. and Tiedje, J. M., "Characterization of the Requirement and Substrates for Reductive dehalogenation by Strain DCB-1," J. Ind. Microbiol. 5, 9-16 (1990). 
6. Mohn, W. W. and Tiedje, J. M., "Microbial Reductive Dehalogenation," Microbial. Rev. 5, 482-507 (1992).

7. Hendriksen, H. V., Larsen, S., and Ahring, B. K., "Influence of a Supplemental Carbon Source on Anaerobic Dechlorination of Pentachlorophenol in Granular Sludge," Appl. Environ. Microbiol. 58, 365-370 (1992).

8. Boyle, A. W., Green, L., and May, H. D., and White, N., "Characterization, Growth, and Stimulation of PCB-Dechlorinating Anaerobes," in 11th Progress Report on the Research and Development Program for the Destruction of PCBs, 227-250, Schenectady, New York: General Electric Company Corporate R\&D Center, 1992.

9. Bedard, D. L., Van Dort, H. M., May, R. J., Principe, J. M., Smullen, L. A., and DeWeerd, K. A., "Bromobiphenyls Stimulate Anaerobic Dechlorination of Aroclor 1260 Contaminant in Sediment Slurries," presented at the 2nd International Symposium for In Situ and On-Site Bioreclamation, San Diego, California, April 5-8, 1993.

10. Shannon, M. J. R., Rothmel, R., Chunn, C. D., and Unterman, R., "Evaluating Polychlorinated Biphenyl Bioremediation Processes: From Laboratory Feasibility Testing to Pilot Demonstrations," in Bioremediation of Chlorinated and Polycyclic Aromatic Hydrocarbons, R. E. Hinchee, A. Leeson, L. Semprini, and S. K. Ong, eds., 354-358. Boca Raton, Florida: Lewis Publishers, 1994.

11. Tiedje, J. M., et al., Biodegradation 4, 231-240 (1993).

12. Klasson, K. T. and Evans, B. S., "PCB Dechlorination in Anaerobic Soil Slurry Reactors," in Papers: IGT's 7th International Symposium for Oil, Gas, and Environmental Biotechnology. Chicago, Illinois: Institute of Gas Technology, in press.

13. Brown, J. F., Wagner, R. E., Feng, H., Bedard, D. L., Brennan, M. J., Carnahan, J. C., and May, R. J., "Environmental Dechlorination of PCBs," Environ. Toxicol. Chem. 6, 579-593 (1987).

14. Shultz, D. E., Petrick, G., and Duinker, J. C., "Complete Characterization of Polychlorinated Biphenyl Congeners in Commercial Aroclor and Chlophen Mixtures by Multidimensional Gas Chromatography - Electron Capture Detector," Environ. Sci. Technol. 23, 852-859 (1989).

15. Bedard, D. L., Wagner, R. E., Brennan, M. J., Haberl, M. L., and Brown Jr., J. F., "Extensive Degradation of Aroclors and Environmentally Transformed Polychlorinated Biphenyls by Alcaligenes eutrophus H850," Appl. Environ. Microbiol. 53, 1094-1102 (1987). 